\title{
Türkiye'de teknolojik pedagojik alan bilgisi üzerine 2009-2013 yılları arasında yapılan çalışmalardaki eğilimler
}

\author{
Cemal Hakan Dikmen \\ Afyon Kocatepe Üniversitesi, Dinar Meslek Yüksekokulu, Afyonkarahisar, Türkiye, \\ c.hakan.dikmen@gmail.com \\ Veysel Demirer \\ Süleyman Demirel Üniversitesi, Eğitim Fakültesi, Isparta, Türkiye, veyseldemirer@gmail.com
}

\begin{abstract}
ÖZ Bu araştırma, Teknolojik Pedagojik Alan Bilgisi (TPAB) ile ilgili Türkiye kaynaklı yapılmış çalışmaları; yayın yılı, yayın türü, araştırma konuları, uygulama alanları, örneklem seçimi, örneklem düzeyi, araştırma yöntemi, veri toplama aracı ve veri analiz yöntemi açısından incelemeyi amaçlamaktadır. Araştırmanın örneklemini 2009-2013 yılları arasında yapılan 32 makale ve 17 tez olmak üzere 49 çalışma oluşturmaktadır. Araştırma kapsamına alınan çalışmalar içerik analizi yapılarak elde edilen sonuçlar araştırma sorularına yanıt verecek şekilde yüzde, frekans gibi betimsel istatistik yöntemleriyle analiz edilmiştir. Elde edilen bulgulara göre, Türkiye'de TPAB ile ilgili yapılan çalışmaların yıllara göre arttığı, öğretmenlerin TPAB düzeylerinden çok öğretmen adaylarının TPAB düzeylerini inceleyen çalışmaların yapıldığı, en çok tercih edilen uygulama alanlarının matematik ve fen olduğu, araştırma yöntemi olarak nicel yöntemlerin daha çok uygulandığı ve veri toplama aracı olarak da anketin daha çok kullanıldığı görülmüştür. Bu çalışmada elde edilen verilerin analizi istatistiksel olarak yorumlanmış; TPAB çerçevesine yaptı̆̆ 1 katkı literatüre dayalı olarak tartışılmıştır.
\end{abstract}

\section{Trends in studies on technological pedagogical content knowledge in Turkey between 2009 and 2013 years}

\begin{abstract}
This study aims to investigate studies about Technological Pedagogical Content Knowledge (TPCK) conducted in Turkey, in terms of publication year, publication type, research topics, implementation areas, sample selection, sampling level, research methodology, data collection instruments and data analysis methods. The sample of the study consists of 49 (32 articles and 17 theses) studies conducted between 2009 and 2013 years. The results obtained through content analysis were analyzed by descriptive statistical methods such as percentage and frequency distributions in order to answer the research questions. According the findings; TPCK related studies in Turkey increased by year, pre-service teachers TPCK levels investigated more than teachers TPCK levels, the most preferred field is mathematics and science in the studies, quantitative methods were applied mostly, and surveys were used more than other data collection instruments. The analysis of the data obtained in this study were interpreted statistically and contribution to the TPCK framework has been discussed based on the literature.
\end{abstract}

Keywords Technological pedagogical content knowledge, studies in Turkey, content analysis. 


\section{EXTENDED SUMMARY}

Nowadays, the rapid development of technology has brought different ideas about technology integration in education, and it has been shown that technological innovation alone is not enough for technology integration in educational environments. Thus, the framework of technological pedagogical content knowledge has been established in order to understand the level of knowledge of teachers, who play a key role in the integration of technology in education. Technological pedagogical content knowledge consists of a combination and interaction of technological knowledge, pedagogical knowledge and content knowledge. Of these, Technology Knowledge (TK) refers to the knowledge about various technologies ranging from ordinary instruction material to advanced digital technologies. Pedagogical Knowledge (PK) includes generic knowledge about the structure, organization, management, and teaching strategies regarding how to teach a specific content domain. The Content Knowledge (CK) is the knowledge to be taught by teachers regarding the topic. Pedagogical Content Knowledge (PCK) is the knowledge about the simulations, illustrations, examples, explanations and demonstrations used by teachers for effective presentation of the content. Technological Content Knowledge (TCK) refers to knowledge about the use of technology to convey the content domain. Technological Pedagogical Knowledge (TPK) refers to the affordances and constraints of technology regarding pedagogical designs and strategies appropriate for disciplinary and developmental aspects. Technological Pedagogical Content Knowledge (TPCK) refers to the knowledge and understanding of the interaction between TK, PK, and CK when using technology for teaching concepts. According to Mishra \& Koehler (2006), the TPCK framework allows teachers to understand the complexity of relationships between concepts when integrating technology with education.

It is seen that there are many studies about TPCK due to contributions of TPCK on teacher competencies regarding technology integration with education, as well as meta-analysis studies analyzing these studies. Wu (2013) investigated the yearly distribution, sampling groups, subject fields and research methodologies of 24 experimental studies about TPCK published in journals indexed by SSCI between 2002 and 2011, and as a result of the analyses he concluded that experimental studies has increased significantly, and most of the studies has been conducted with pre-service teachers, instead of working teachers. Voogt, Fisser, Pareja Roblin, Tondeur, and van Braak (2013) have analyzed 55 studies on TPACK published between 2005 and 2011 in Education Resources Information Center (ERIC), Web of Science, Scopus, and PsychINFO databases in terms of theoretical foundations and practical uses, and as a result of the analysis of findings concluded that there are different understandings of TPCK and TK, leading various views regarding the measurement of TPCK, the concepts related to TPCK are hard to understand, thoughts about TPCK, PK and TK are intertwined, and technology-enriched courses based on active participation is a promising strategy for improving TPCK of teachers. It has been seen that evaluation of various studies on TPCK conducted worldwide makes a major contribution to the literature. As much as being a summary of the studies carried out so far, these studies which examines the studies about TPCK are expected to shed light on future studies. In this context, this study aims to investigate studies about TPCK conducted in Turkey, in terms of publication year, publication type, research topics, implementation areas, sample selection, sampling level, research methodology, data collection instruments and data analysis methods. The sample of the study consists of Turkey-based articles published between 2009 and 2013 in journals indexed by SSCI and ULAKBIM (National Academic Network and Information Center of Turkey) database, as well as theses published in full text in the YÖK (The Council of Higher Education) thesis database. In order to determine the studies to be investigated within the scope of the research, the keywords "Technological Pedagogical Content Knowledge", and "TPCK" were searched in SSCI Journals, ULAKBIM and YÖK thesis databases. This search yielded 49 studies, consisting of 32 articles and 17 theses. Data obtained by examining the studies within the scope of this research were recorded in an electronic form into the publication classification form of TPCK, and the results obtained through content analysis were analyzed by descriptive statistical methods such as percentage and frequency distributions in order to answer the research questions.

According to results, an increase in the number of studies conducted on TPCK is on the rise in Turkey between 2009 and 2013 years. And, this indicates an increasing tendency towards TPCK research in Turkey. The relationship between achievement levels, various demographic variables (age, gender, experience etc.) and TPCK, the relationships between technology integration in education and TPCK, the effects of course, workshop, instruction, etc. practices on the development of TPCK are the most 
researched topics in TPCK-related studies. Mathematics and science were found to be the most preferred application areas according to the majority of the research. Looking at the levels of sampling, it's observed that the majority of studies investigated levels of TPCK of pre-service teachers, rather than branch teachers or primary school teachers. Considering the research methodologies, it's understood that quantitative methods were applied mostly; and, among the data analysis methods, descriptive analysis method was found to be the preferred qualitative analysis method, compared to other data analysis approaches. And, looking at the data collection instruments, it's seen that questionnaires and interview forms were used more than other data collection instruments. In this context, it's understood that studies on TPCK are increasing in number and variety day by day, and future studies are needed to be conducted with different methods in different domains. Since there were many studies investigating the relationship between various demographic variables and achievement levels in TPCK, there is a need for studies on different subject areas.

As in the fields of mathematics and science, studies on TPCK in other fields should be increased, particularly in the field of information technology, which plays a key role in the integration of technology with education. When considered in the context of technology integration with education, it is extremely important to increase studies on the levels of TPCK of working teachers, as much as the studies conducted with pre-service teachers. Focusing on qualitative and mixed-type studies, as well as quantitative studies to be conducted about TPCK will make a great contribution to the literature. As a result, it is thought that investigation of studies on TPCK within the context mentioned above will contribute to the literature, will reveal the differences and similarities between the studies, and will shed a light on future studies. 


\section{GİRIŞ}

Günümüzde teknolojinin hızla ilerlemesi eğitime teknoloji entegrasyonu konusunda da farklı fikirleri beraberinde getirmiştir. Eğitime teknolojik yenilik getirmeyi sorguladığımızda, bu yeniliğin pedagoji, insan ve performans boyutlarını içerdiğini görmekteyiz (Ferdig, 2006). Bu bağlamda eğitime teknoloji entegrasyonunda sadece teknolojinin değişimi tek başına sağlamadığı (Koehler ve Mishra, 2005), öğretmenlerin teknolojiyi kullanma şeklinin eğitimi değiştirme potansiyeline sahip olduğu görülmektedir (Carr, Jonassen, Litzinger ve Marra, 1998). Sınıf içi öğretme etkinliklerini planlama ve uygulamada öğretmenin niteliği, yeterliği ve deneyimi önemli yer tutmaktadır (Demir ve Bozkurt, 2011). Bunlara bakarak eğitime teknoloji entegrasyonu sürecinde, öğretmen yeterliliğinin son derece önemli olduğunu söyleyebiliriz.

Shulman (1987) öğretmen yeterliklerinin; alan bilgisi, pedagojik bilgi, pedagojik alan bilgisi, müfredat bilgisi, öğrenen özellikleri bilgisi, eğitsel bağlam bilgisi, eğitsel çıktılar, amaçlar, değerler, felsefik ve tarihi temeller hakkında bilgi başlıklarını içermesi gerektiğini belirtmiştir. Shulman'ın (1987) öğretmen yeterliliklerinde belirtmiş olduğu pedagojik alan bilgisi kavramına, Koehler ve Mishra (2005) teknolojik bilgi kavramını da dahil ederek Teknolojik Pedagojik Alan Bilgisi (Technological Pedagogical Content Knowledge - TPACK) çerçevesini oluşturmuşlardır. Teknolojik Pedagojik Alan Bilgisi (TPAB), Teknolojik Bilgi (TB), Pedagojik Bilgi (PB) ve Alan Bilgisinin (AB) birleşimi olmakla birlikte, TPAB her bir parçanın toplamından daha anlamlı bir bütünü ifade etmektedir (Koehler \& Mishra, 2005). TB; sıradan ders materyallerinden, gelişmiş dijital teknolojilere kadar sıralanabilecek çeşitli teknolojiler hakkındaki bilgidir (Pamuk, Ülken ve Dilek, 2012). PB; belirli bir konu alanının nasıl öğretileceğiyle ilgili yapı, organizasyon, yönetim ve öğretim stratejileri hakkındaki bilgidir (Wetzel, Foulger ve Williams, 2008-2009). AB; konu alanıyla ilgili öğretmenin ne öğreteceği hakkındaki bilgidir (Mishra ve Koehler, 2006; Wetzel vd., 2008-2009; Baran, Chuang ve Thompson, 2011). PAB; öğretmenin ders anlatırken kullandı̆̆ı; konuların etkili sunumu, güçlü benzeşimler, çizimler, örnekler, açıklamalar ve gösteriler hakkındaki bilgidir (Shulman, 1986). TAB; konunun teknolojik araçlar ile dönüşümünün sağlanması hakkındaki bilgidir (Koehler ve Mishra, 2009; Kereluik, Mishra ve Koehler, 2011; Pamuk vd., 2012). TPB; disiplinsel ve gelişimsel açıdan uygun pedagojik tasarım ve stratejilerle ilgili olarak, bir dizi teknolojik aracın pedagojik olanakları ve sinıllılıkları hakkındaki bilgidir (Koehler ve Mishra, 2009). TPAB; TB, PB, AB bilgi alanlarının etkileşiminden ortaya çıkan ve teknolojiyi kullanarak kavramların nasıl öğretileceği hakkındaki anlayışla ilgili bilgidir (Mishra ve Koehler, 2006; Kereluik vd., 2011). TPAB boyutlarının birbirleri arasındaki ilişkiyi açıklayan TPAB çerçevesi Şekil 1'de görülmektedir (Koehler ve Mishra, 2005).

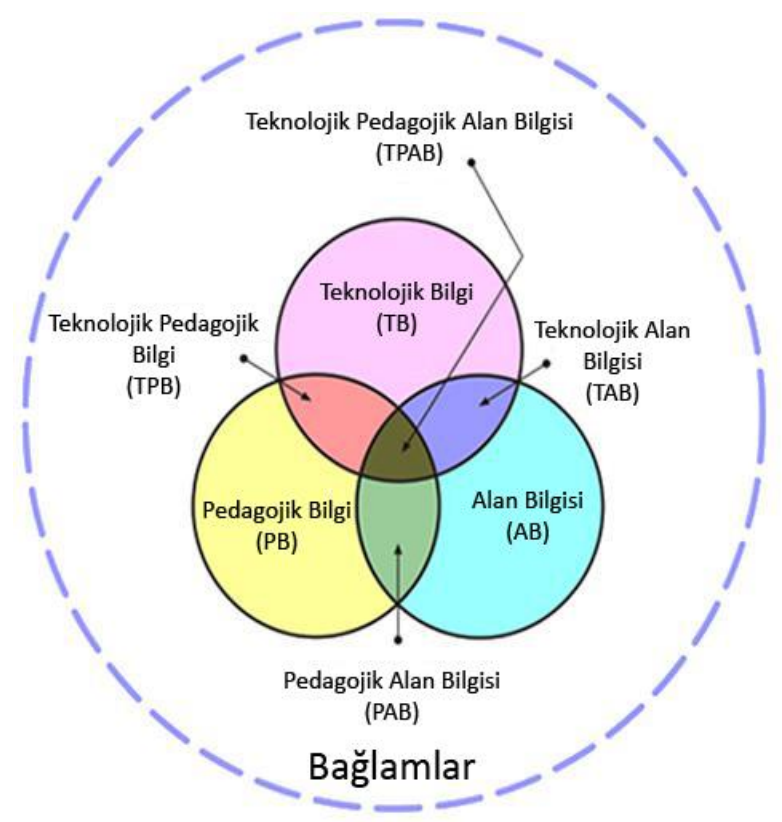

Şekil 1. Teknolojik Pedagojik Alan Bilgisi (Koehler, 2012) 
Mishra ve Koehler'e (2006) göre eğitime teknoloji entegrasyonunda TPAB çerçevesi; öğretmenlere kavramlar arasındaki karmaşık ilişkiler arasında mantık kurmaya olanak sağlamaktadır. TPAB'ın eğitime teknoloji entegrasyonunda öğretmen yeterliklerine katkısı nedeniyle, TPAB'la ilgili birçok çalışma yapıldığ 1 ve bunun yanında yapılan bu çalışmaları inceleyen çalışmalar da yapıldığı görülmektedir. Wu (2013), 2002-2011 yılları arasında SSCI kapsamındaki dergilerde yayınlanmış TPAB ile ilgili 24 deneysel çalışmanın; yıllara göre dağılımını, örneklem gruplarını, konu alanlarını ve araştırma yöntemlerini incelemiş; analizlerin sonucunda deneysel çalışmaların anlamlı bir şekilde arttığı, öğretmenlerden çok öğretmen adayları üzerinde çalışma yapıldığı sonucuna varmıştır. Voogt, Fisser, Pareja Roblin, Tondeur ve van Braak (2013), 2005-2011 yılları arasında Education Resources Information Center (ERIC), Web of Science, Scopus ve PsychINFO veri tabanlarında yer alan TPAB ile ilgili yapılmış 55 çalışmayı TPAB'ın kuramsal temelleri ve pratik kullanımı açısından incelemiş; bulguların analizinde, TPAB ve TB'ye yönelik farklı anlayışların olduğu, bunun TPAB'ın ölçülmesinde farklı görüşler olmasını da etkilediği, TPAB ile ilgili kavramların zor anlaşıldığı TPAB, PB ve TB hakkındaki inançların iç içe geçtiği, aktif katılımlı yeniden tasarlanan teknolojiyle zenginleştirilmiş derslerin öğretmenlerin TPAB gelişimi için umut verici bir strateji olduğu sonuçlarına ulaşmıştır.

Dünya'da TPAB ile ilgili yapılmış çeşitli çalışmaların incelenerek yorumlanmasının literatüre büyük bir katkı sağladığı görülmüştür. TPAB ile ilgili yapılmış çalışmaların incelendiği çalışmalar (Voogt vd., 2013; Wu, 2013); bugüne kadar yapılan çalışmaların bir özeti olduğu gibi, bu tarz çalışmaların gelecekte yapılacak ilgili çalışmalara da örneklem grupları, araştırılan konu alanları, araştırma yöntemleri, kuramsal temeller ve bunların uygulamaları bağlamında 1şık tutacağı düşünülmektedir. Bu bağlamda, bu araştırmada TPAB ile ilgili yapılmış Türkiye adresli çalışmaların ortaya konulması ve çeşitli değişkenler açısından incelenmesi amaçlanmaktadır. Araştırmanın amacı doğrultusunda aşağıdaki sorulara yanıt aranmıştır:

TPAB ile ilgili yapılmış çalışmalar yıllara göre farklılık göstermekte midir?

TPAB ile ilgili yapılmış çalışmalarda hangi konular araştırılmıştır?

TPAB ile ilgili yapılmış çalışmalar uygulanan branşlara göre farklılık göstermekte midir?

TPAB ile ilgili yapılmış çalışmalar örneklem seçimlerine göre farklılık göstermekte midir?

$T P A B$ ile ilgili yapılmış çalışmalar örneklem düzeylerine göre farklılık göstermekte midir?

TPAB ile ilgili yapılmış çalışmalarda hangi yöntemler yaygın olarak kullanılmışıtır?

TPAB ile ilgili yapılmış çalışmalarda hangi veri toplama araçları tercih edilmiştir?

TPAB ile ilgili yapılmış çalışmalarda hangi veri analizi yöntemleri yaygın olarak kullanılmıştır?

\section{YÖNTEM}

TPAB ile ilgili yapılmış Türkiye adresli çalışmaların inceleneceği bu araştırmada nitel araştırma desenlerinden doküman inceleme yöntemi kullanılmış; toplanılan verileri açıklayabilmek için gerekli kavram ve ilişkilere ulaşmak amacıyla nitel analiz yöntemlerinden içerik analizi yöntemi kullanılmıştır. $\mathrm{Bu}$ çalışmada içerik analizi yöntemi kullanılmasının nedeni araştırma için toplanılan verilerin önce kavramsallaştırılması, sonrasında ortaya çıkan kavramlara göre mantıksal olarak şekillendirilmesi ve buna göre verileri açıklayan temaların belirlenmesi gerekmektedir. İçerik analizi verileri tanımlamamızı ve belirli çerçevelerde bir araya getirmemizi sağlamaktadır (Yıldırım ve Şimşek, 2011, s. 227). Araştırmanın kapsamı, veri toplama süreci ve veri analiz işlemler bu bölümde belirtilmiştir.

\section{Araştırmanın Kapsamı}

Araştırmanın kapsamını 2009-2013 yılları arasında Teknolojik Pedagojik Alan Bilgisi ile ilgili yapılmış Türkiye adresli çalışmalar oluşturmaktadır. Bu bağlamda araştırma; SSCI kapsamındaki dergilerde yayınlanmış makaleleri, ULAKBİM ulusal veri tabanlarında dizinlenen eğitim bilimleri dergilerinde yayınlanmış makaleler ile YÖK tez veri tabanında yayınlanmış tezleri kapsamaktadır.

\section{Veri Toplama Süreci}

Araştırma kapsamında incelenecek çalışmaları belirlemek amacıyla SSCI kapsamındaki dergilerde, Ulakbim ve YÖK tez veritabanında "Teknolojik Pedagojik Alan Bilgisi", "TPAB", "Technological Pedagogical Content Knowledge" ve "TPACK" anahtar sözcükleri kullanılarak tarama yapılmıştır. Tarama sonucunda TPAB ile ilgili 25 farklı dergide 32 makale, YÖK tez veritabanında ise 14'ü yüksek lisans, 3'ü doktora tezi olmak üzere toplamda 17 tez çalışması tespit edilmiş ve araştırma kapsamında 
incelenmiştir. Elde edilen tüm çalışmaların bulunduğu dergiler ve yıllara göre dağılımı Ek 1'de ve tam referanslarını içeren liste Ek 2'de sunulmuştur.

Araştırma kapsamına alınması kararlaştırılan çalışmalardan ayrı ayrı incelenerek elde edilen veriler, Göksu, Özcan, Çakır ve Göktaş (2014) tarafından geliştirilen "Öğretim Tasarımı Modeli Yayın Sinıflandırma Formu"ndan (ÖTMYSF) yararlanılarak oluşturulan "Teknolojik Pedagojik Alan Bilgisi Yayın Sınıflandırma Formu"na (TPABYSF) elektronik ortamda kaydedilmiştir. Böylece çalışmanın güvenirliği ve iç geçerliği sağlanmaya çalışılmıştır. TPABYSF'de yayın türü, yayın yeri, yıl, yöntem, veri toplama aracı, örneklem sayısı, örneklem seçim şekli, örneklem düzeyi, uygulama alanı, araştırma konusu ve veri analiz yöntemi başlıkları yer almaktadır.

\section{Veri Analizi}

Tarama sonucunda TPAB ile ilgili olduğu tespit edilen 49 çalışma; araştırma konusu, veri analiz yöntemi, veri toplama aracı, TPAB'ın incelendiği alanlar, örneklem seçimi, örneklem düzeyi ve kullanılan yöntemler açısından incelenmiştir. Araştırma sürecinde yapılan içerik analizi sonucunda elde edilen veriler, araştırmacılar tarafından araştırma sorularına yanıt verecek şekilde belirlenen temalara göre betimsel istatistik yöntemleri (yüzde, frekans vb.) kullanılarak çözümlenmiştir. Elde edilen verilerin frekans ve yüzde oranları, araştırma sorularına yanıt verecek şekilde araştırmacılar tarafından hesaplanmış, kodlayıcılar arasında güvenirliği sağlamak için Miles ve Huberman'ın (1994) belirlemiş olduğu "güvenirlik=görüş birliği/(görüş birliği i+görüş ayrıllı̆ı)" formülünden yararlanılmış, temalar için kodlama güvenirliği oranlarının her bir tema için \%90'nın üzerinde olduğu tespit edilmiştir. Güvenirlik hesaplamalarının \%70'in üzerinde çıkması, araştırmanın güvenilir olarak kabul edilmesi için yeterli görülmektedir (Miles ve Huberman, 1994). Elde edilen veriler düzenlenmiş, gruplanmış, sayısal hale getirilerek tablolar halinde sunulmuş ve son olarak ortaya çıkan bulgular yorumlanmıştır.

\section{BULGULAR}

Bu bölümde TPAB ile ilgili yapılmış çalışmalarla ilgili; yayın yılı, araştırma yöntemi, veri toplama aracı, veri analiz yöntemi, araştırma konuları, uygulama alanları, örneklem seçimi, örneklem düzeyi ve kullanılan yöntemlere ait bulgulara yer verilmiştir. TPAB ile ilgili yapılmış çalışmaların yıllara göre dağılımlarını belirtmek amacıyla, her bir yıla ait istatistikler Tablo 1'de sunulmuştur.

Tablo 1. TPAB ile İlgili Yapılmış Çalışmaların Yıllara Göre Dağılımı

\begin{tabular}{ccccccc}
\hline & 2009 & 2010 & 2011 & 2012 & 2013 & Toplam \\
\hline Makale & 1 & 1 & 6 & 8 & 16 & 32 \\
Tez & 2 & 1 & 6 & 5 & 3 & 17 \\
Toplam & 3 & 2 & 12 & 13 & 19 & 49 \\
\hline
\end{tabular}

TPAB ile ilgili yapılmış çalışmaların yıllara göre dağılımına ait betimsel istatistiklere bakıldığında, TPAB ile ilgili yapılan çalışmaların toplam sayılarında yıllara göre artış olduğu görülmektedir. Yayın sayısındaki bu artışa bakarak Türkiye'de TPAB konusuna olan eğilimin arttığını söyleyebiliriz.

\section{Araştırma Konularına Göre TPAB ile İlgili Yapılmış Çalışmalar}

TPAB ile ilgili yapılmış çalışmalar araştırma konularına göre incelenmiştir. Araştırma konularının toplam frekansının 58 olmasının sebebi, bazı araştırmalarda birden fazla konunun araştırılmış olmasıdır. Araştırma konularına ait betimsel istatistikler Tablo 2'de sunulmuştur.

Tablo 2. Araştırma Konularının Dağılımı

\begin{tabular}{|c|c|c|}
\hline Araştırma Konusu & $f$ & $\%$ \\
\hline $\begin{array}{l}\text { Çeşitli demografik değişkenler ve TB, PB, AB, TPB, TAB, PAB, TPAB bilgisi } \\
\text { düzeyleri arasındaki ilișki }\end{array}$ & 18 & 31.04 \\
\hline Eğitime teknoloji entegrasyonu ve ТРАВ arasındaki ilişkiler & 11 & 18.97 \\
\hline Kurs, çalıştay, ders vb. eğitim uygulamalarının ТPAB gelişimine etkisi & 11 & 18.97 \\
\hline Ölçek geliștirme ve çeviri çalışmaları & 9 & 15.51 \\
\hline Farklı konu alanlarında TPAB düzeyleri & 9 & 15.51 \\
\hline Toplam & 58 & 100 \\
\hline
\end{tabular}


Tablo 2 incelendiğinde TPAB ile ilgili yapılmış çalışmalarda en çok araştırılan konunun yaş, cinsiyet, akademik başarı, deneyim, branş gibi çeşitli demografik değişkenler ve TPAB çerçevesinin bileşenleri arasındaki ilişki ( $\mathrm{f}=18)$ olduğu görülmektedir. Eğitime teknoloji entegrasyonu ve TPAB arasındaki ilişkiler ( $\mathrm{f}=11)$, kurs, çalıştay, ders vb. eğitim uygulamalarının TPAB gelişimine etkisi $(\mathrm{f}=11)$ konularının ise ölçek geliştirme ve çeviri ile farklı alanlarda TPAB düzeyleri gibi konulara oranla daha fazla araştırıldığı, ölçek geliştirme ve çeviri çalışmalarının $(\mathrm{f}=9)$ ve farklı konu alanlarında TPAB düzeylerini inceleyen çalışmaların ( $\mathrm{f}=9$ ) daha az yapıldığı görülmektedir.

\section{Uygulama Alanlarına Göre TPAB ile İlgili Yapılmış Çalışmalar}

TPAB ile ilgili yapılmış çalışmalardan alan yazın derleme çalışması (Kaya ve Yılayaz, 2013) dışında kalan 48 çalışma uygulandığı alanlara göre incelenmiş, TPAB ile ilgili çalışmaların hangi alanlarda uygulandığına dair istatistiksel bilgiler Tablo 3 'te verilmiştir.

Tablo 3. Uygulama Alanlarının Dağılımı

\begin{tabular}{lcc}
\hline \multicolumn{1}{c}{ Branş } & $f$ & $\%$ \\
\hline Matematik & 19 & 20.43 \\
Fen ve Teknoloji & 13 & 13.98 \\
Sinıf & 10 & 10.75 \\
İngilizce & 8 & 8.60 \\
Sosyal Bilgiler & 8 & 8.60 \\
Bilgisayar ve Öğretim Teknolojileri & 5 & 5.37 \\
Fizik & 4 & 4.30 \\
Okul Öncesi & 4 & 4.30 \\
Kimya & 3 & 3.23 \\
Biyoloji & 2 & 2.15 \\
Beden Eğitimi & 2 & 2.15 \\
Resim & 2 & 2.15 \\
Müzik & 2 & 2.15 \\
Teknoloji Tasarım & 2 & 2.15 \\
Coğrafya & 1 & 1.08 \\
Din Kültürü ve Ahlak Bilgisi & 1 & 1.08 \\
Özel Eğitim & 1 & 1.08 \\
Tarih & 1 & 1.08 \\
Branş Belirtilmemiş & 5 & 5.37 \\
& 93 & 100 \\
\hline
\end{tabular}

Tablo 3 incelendiğinde TPAB ile ilgili yapılmış çalışmaların uygulama alanlarına göre farklılık gösterdiği ve en çok çalışma yapılan alanın Matematik ( $\mathrm{f}=19)$ olduğu görülmektedir. Bununla birlikte, Fen ve Teknoloji ( $\mathrm{f}=13$ ), Sınıf ( $\mathrm{f}=10$ ), İngilizce $(\mathrm{f}=8)$ ve Sosyal Bilgiler ( $\mathrm{f}=8$ ) ile ilgili çalışmaların; Bilgisayar ve Ögretim Teknolojileri ( $\mathrm{f}=5$ ), Fizik ( $\mathrm{f}=4)$, Okul Öncesi ( $\mathrm{f}=4)$, Kimya $(\mathrm{f}=3)$, Biyoloji $(\mathrm{f}=2)$, ve Beden Eğitimi ( $\mathrm{f}=2)$, Resim ( $\mathrm{f}=2)$, Müzik ( $\mathrm{f}=2$ ), Teknoloji Tasarım ( $\mathrm{f}=2$ ), Coğrafya $(\mathrm{f}=1)$, Din Kültürü ve Ahlak Bilgisi ( $\mathrm{f}=1)$, Özel Eğitim ( $\mathrm{f}=1$ ) ve Tarih ( $\mathrm{f}=1)$ alanlarıyla ilgili çalışmalardan fazla olduğu tespit edilmiştir.

\section{Örneklem Seçimine Göre TPAB ile İlgili Yapılmış Çalışmalar}

TPAB ile ilgili yapılmış çalışmalardan alan yazın derleme çalışması dışında kalan 48 çalışma örneklem seçimine göre incelenmiş, TPAB ile ilgili çalışmalarda hangi örneklem seçim yöntemleri kullanıldığına dair betimsel istatistikler Tablo 4'te verilmiştir.

Tablo 4. Örneklem Seçimi

\begin{tabular}{|c|c|c|}
\hline Örnekleme Yöntemi & $f$ & $\%$ \\
\hline Kolay ulaşılabilir & 35 & 72.92 \\
\hline Amaca uygun & 7 & 14.58 \\
\hline Rastgele & 6 & 12.50 \\
\hline Toplam & 48 & 100 \\
\hline
\end{tabular}


Tablo 4 incelendiğinde TPAB ile ilgili yapılmış çalışmaların örnekleme yöntemlerine göre farklılık gösterdiği, en çok kolay ulaşılabilir örnekleme yönteminin ( $\mathrm{f}=35)$ tercih edildiği, amaca uygun $(\mathrm{f}=7)$ ve rastgele $(\mathrm{f}=6)$ örnekleme yönteminin ise daha az tercih edildiği görülmektedir.

\section{Örneklem Düzeyine Göre TPAB ile İlgili Yapılmış Çalışmalar}

TPAB ile ilgili yapılmış çalışmalardan alan yazın derleme çalışması dışında kalan 48 çalışma örneklem düzeyine göre incelenmiş, ТPAB ile ilgili çalışmalarda hangi örneklem düzeylerinde araştırma yapıldığına dair betimsel istatistikler Tablo 5 'te verilmiştir.

Tablo 5. Örneklem Düzeyi

\begin{tabular}{lcc}
\hline Örneklem Düzeyleri & $f$ & $\%$ \\
\hline Öğretmen adayları & 37 & 77.09 \\
Öğretmen & 10 & 20.83 \\
Akademisyen & 1 & 2.08 \\
\multicolumn{1}{r}{ Toplam } & 48 & 100 \\
\hline
\end{tabular}

Tablo 5 incelendiğinde TPAB ile ilgili yapılmış çalışmaların örneklem düzeylerine göre farklılık gösterdiği; en çok öğretmen adaylarının ( $\mathrm{f}=37)$ TPAB'ının araştırıldığ akademisyenlerin $(\mathrm{f}=1)$ TPAB'ını inceleyen çalışmaların ise daha az yapıldığı görülmektedir.

\section{TPAB ile İlgili Yapılmış Çalıșmalarda Kullanılan Yöntemler}

TPAB ile ilgili yapılmış çalışmalardan alan yazın derleme çalışması dışında kalan 48 çalışma, çalışmada kullanılan yöntemlere göre incelenmiş, nicel ve nitel yöntemleri birlikte kullanan çalışmaların yöntemi karma (mixed) (Creswell, 2003) olarak belirtilmiştir. TPAB ile ilgili çalışmalarda uygulanan yöntemlerin yıllara göre değişimini gösteren betimsel istatistikler Şekil 2'de verilmiştir.

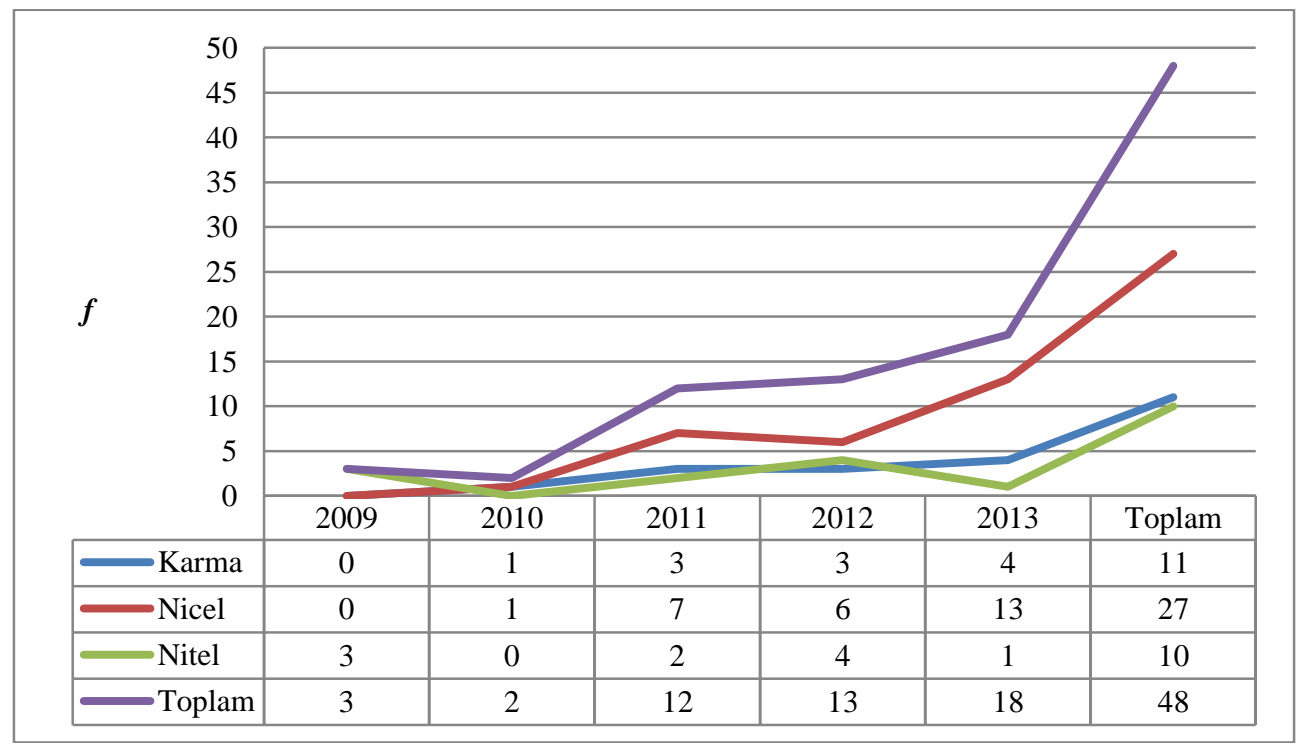

Şekil 2. Kullanılan Yöntemlerin Yıllara Göre Dağılımı

Şekil 2 incelendiğinde TPAB ile ilgili yapılmış olan nicel çalışmaların ( $\mathrm{f}=27)$ diğer çalışmalardan fazla olduğu, karma yöntemlerin ( $\mathrm{f}=11$ ) ve nitel yöntemlerin ( $\mathrm{f}=10)$ çalışmalarda daha az tercih edildiği görülmektedir. Çalışmaların yıllara göre dağılımına bakıldığında ise nitel yöntemlerin artık daha az tercih edildiği, nicel ve karma yöntemlerin ise daha çok tercih edilmeye başlandığg görülmektedir.

\section{TPAB ile İlgili Yapılmış Çalışmalarda Kullanılan Veri Toplama Araçları}

TPAB ile ilgili yapılmış çalışmalardan alan yazın derleme çalışması dışında kalan 48 çalışma, çalışmada kullanılan veri toplama araçlarına göre incelenmiştir. Veri toplama araçlarının toplam frekansının 79 olmasının sebebi, araştırmaların çoğunda birden fazla veri toplama aracı kullanılmış olmasıdır. Veri toplama araçlarına ait betimsel istatistikler Tablo 6'da sunulmuştur. 
Tablo 6. Kullanılan Veri Toplama Araçlarının Dağılımı

\begin{tabular}{|c|c|c|}
\hline Veri Toplama Aracı & $f$ & $\%$ \\
\hline Anket & 41 & 51.90 \\
\hline Görüşme Formu & 19 & 24.05 \\
\hline Doküman & 9 & 11.39 \\
\hline Gözlem Formu & 7 & 8.86 \\
\hline Başarı Testi & 3 & 3.80 \\
\hline Toplam & 79 & 100 \\
\hline
\end{tabular}

Tablo 6 incelendiğinde TPAB ile ilgili yapılmış çalışmalarda veri toplama aracı olarak en çok anket $(\mathrm{f}=41)$ kullanımının tercih edildiği, görüşme formu ( $\mathrm{f}=19$ ), doküman $(\mathrm{f}=9)$, gözlem formu $(\mathrm{f}=7)$ ve başarı testi $(\mathrm{f}=3)$ gibi veri toplama araçlarının ise daha az tercih edildiği görülmektedir.

\section{TPAB ile İlgili Yapılmış Çalışmalarda Kullanılan Veri Analizi Yöntemleri}

TPAB ile ilgili yapılmış çalışmalardan alan yazın derleme çalışması dışında kalan 48 çalışma, çalışmada kullanılan veri analizi yöntemlerine göre incelenmiştir. Veri analizi yöntemlerinin toplam frekansının 88 olmasının sebebi, bazı araştırmalarda birden fazla veri analizi yöntemi kullanılmış olmasıdır. Çalışmalarda kullanılan veri analizi yöntemlerinin dağılımına ait betimsel istatistikler Tablo 7'de sunulmuştur.

Tablo 7. Kullanılan Veri Analizi Yöntemlerinin Dağılımı

\begin{tabular}{llcc}
\hline \multicolumn{2}{c}{ Veri Analiz Yöntemi } & f & $\%$ \\
\hline \multirow{2}{*}{ Nicel } & Betimsel Analiz & 37 & 42.05 \\
& Kestirimsel Analiz & 31 & 35.23 \\
\multirow{2}{*}{ Nitel } & İçerik Analizi & 13 & 14.77 \\
& Betimsel Analiz & 7 & 7.95 \\
& Toplam & 88 & 100 \\
\hline
\end{tabular}

Tablo 7'deki veriler incelendiğinde, TPAB ile ilgili Türkiye'de yapılmış çalışmalarda, en çok tercih edilen veri analiz yönteminin nicel analiz yöntemlerinden betimsel analiz yöntemi ( $f=37)$ olduğu, kestirimsel analiz yöntemlerinin ise $(\mathrm{f}=31)$ daha az tercih edildiği görülmektedir. Nitel analiz yöntemlerinden içerik analizi yöntemi $(\mathrm{f}=13)$ ise betimsel analiz yöntemine $(\mathrm{f}=7)$ göre daha çok tercih edilmektedir.

\section{TARTIŞMA}

Araştırmadan elde edilen bulgular TPAB ile ilgili Türkiye'de yapılan çalışmaların yıllara göre arttı̆̆ını, araştırılan konular bakımından çeşitlilik gösterdiğini, hemen hemen her alanda uygulanmasına rağmen fen ve matematik alanlarında daha fazla çalışma yapıldığını ayrıca öğretmenlerden çok öğretmen adaylarının TPAB düzeylerini inceleyen çalışmaların yer aldığını göstermektedir. Bununla birlikte; TPAB ile ilgili Türkiye'de yapılmış çalışmalarda kullanılan örneklem seçimi, veri toplama aracı seçimi ve veri analizi yöntemlerinin; Türkiye'de yapılmış farklı alanlardaki çalışmaların örneklem seçimi, veri toplama aracı seçimi ve veri analizi yöntemleriyle benzerlik gösterdiği tespit edilmiştir (Göksu vd., 2014; Göktaş vd., 2012).

Wu (2013) çalışmasında; matematik ve fen alanlarında diğer branşlara oranla daha fazla TPAB ile ilgili çalışma yapıldığını tespit etmiştir. Türkiye'de TPAB ile ilgili yapılan çalışmalarda olduğu gibi Dünya'da yapılan çalışmalarda da matematik ve fen alanlarına yönelik çalışmaların diğer alanlarda yapılan çalışmalardan fazla olması, diğer alanlara yönelik TPAB ile ilgili çalışmalara duyulan ihtiyacı göstermektedir.

Türkiye'de TPAB ile ilgili yapılmış çalışmaların örneklem düzeylerine ait bulgular incelendiğinde; Türkiye ve Türkiye dışındaki ülkelerde yapılan çalışmalarda öğretmenlerden çok öğretmen adaylarının TPAB düzeylerini araştıran çalışmaların yer aldığı anlaşılmaktadır. Wu (2013) TPAB ile ilgili yapılmış deneysel çalışmaları incelediği çalışmasında öğretmenlerden çok öğretmen adaylarına yönelik çalışmaların yer aldığını tespit etmiştir. Öğretmen adaylarının örneklem grubu olarak kolay ulaşılabilir olması veya öğretmenlere yönelik çalışma yapmanın göreceli zorluğu, TPAB ile ilgili yapılmış çalışmaların öğretmenlerden çok öğretmen adaylarına yönelik olmasının nedenleri arasında olduğu 
söylenebilir. Benzer şekilde kolay ulaşılabilir örnekleme yönteminin yaygın olarak tercih edilmesinin sebebi yöntemin araştırmaya hız ve pratiklik kazandırmasının yanı sıra maliyet ve ulaşılabilirlik açısından kolay olarak algılanmasıdır (Yıldırım ve Şimşek, 2011, s.113). Ancak eğitime teknoloji entegrasyonu bağlamında bakıldığında öğretmenlerin TPAB düzeylerine yönelik çalışmaların göreceli olarak azlığ bir eksiklik olarak görülmektedir.

Türkiye ve Türkiye dışındaki ülkelerde yapılmış TPAB ile ilgili çalışmalarda kullanılan araştırma yöntemleri açısından baktığımızda; Türkiye'de yapılan çalışmalarda nicel yöntemlerin ( $\mathrm{f}=27)$, karma $(\mathrm{f}=11)$ ve nitel ( $\mathrm{f}=10)$ yöntemlere göre daha fazla tercih edilmesine rağmen, $\mathrm{Wu}(2013)$, TPAB ile ilgili yapılmış deneysel çalışmalarda nitel $(\mathrm{f}=10)$ ve nicel $(\mathrm{f}=11)$ çalışma sayısının hemen hemen birbirine yakın olduğunu tespit etmiştir. TPAB ile ilgili Türkiye'de yapılmış çalışmalarda veri toplama aracı olarak anketin ( $\mathrm{f}=41)$, diğer veri toplama araçlarına göre farklı bölgelerde daha düşük maliyetle daha büyük gruplara, daha hızlı bir şekilde uygulanabildiği için araştırmalarda yaygın olarak tercih edildiği (Büyüköztürk, Kılıç Çakmak, Akgün, Karadeniz ve Demirel, 2013), TPAB ile ilgili Türkiye'de yapılmış çalışmalarda da benzer nedenlerle veri toplama aracı olarak anketin yaygın olarak kullanıldığı düşünülmektedir.

Türkiye'de TPAB ile ilgili yapılmış çalışmalarda en çok kullanılan veri analiz yönteminin; nicel veri analiz yöntemlerinden betimsel analiz olduğu görülmektedir. Türkiye'de yapılmış farklı alanlardaki çalışmaları inceleyen çalışmalarda; nicel veri analiz yöntemlerinden betimsel analiz yönteminin daha çok kullanıldığını tespit eden araştırmalar olduğu gibi (Göktaş vd., 2012; Varışoğlu, Şahin ve Göktaş, 2013), nicel veri analiz yöntemlerinden kestirimsel analiz yönteminin daha fazla kullanıldığını tespit eden bir çalışma (Göksu vd., 2014) da bulunmaktadır. TPAB ile ilgili Türkiye'de yapılmış çalışmalarda veri analiz yöntemi olarak nicel analiz yöntemlerinden betimsel analiz yönteminin daha çok tercih edilmesinin, TPAB çalışmalarının daha çok TPAB düzeylerini tanımlamaya yönelik olmasından kaynaklandığı söylenebilir. Bununla birlikte alanda TPAB ilgili nicel ve nitel desenlerin birlikte kullanıldığ 1 karma desenli çalışmalara ihtiyaç duyulduğu görülmektedir. Nicel ve nitel yöntemlerin birlikte kullanıldığı çalışmalar TPAB düzeylerine yönelik daha sağlıklı sonuçlar verdiği gibi TPAB ile ilgili yapılacak diğer çalışmalara da büyük katkı sağlayacaktır.

\section{SONUÇ VE ÖNERILLER}

Bu çalışmada Türkiye'de TPAB ile ilgili yapılan çalışmalar; yayınlandıkları yıl, araştırdı̆̆ 1 konu, uygulandıkları alan, örneklem düzeyi, kullanılan yöntem, veri toplama aracı ve veri analizi yöntemine göre incelenmiş olup araştırmanın sonuçları şu şekildedir:

- TPAB ile ilgili Türkiye'de yapılan çalışmalar yıllara göre artış göstermektedir.

- TPAB ile ilgili Türkiye'de yapılmış çalışmalarda en çok araştırılan konunun, çeşitli demografik değişkenler ve başarı düzeyleriyle TPAB arasındaki ilişki olduğu görülmektedir.

- Matematik ve fen alanlarında daha çok araştırma yapıldığı tespit edilmiştir.

- Örneklem seçiminde kolay ulaşılabilir örneklem yönteminin daha çok tercih edildiği görülmektedir.

- Öğretmenlerden çok öğretmen adaylarının TPAB düzeylerini inceleyen çalışmaların yapıldığı tespit edilmiştir.

Yapılan çalışmalarda araştırma yöntemlerinden nicel araştırma yöntemleri, veri toplama aracı olarak anket ve veri analizi yöntemi olarak da nicel yöntemlerden betimsel veri analizi yöntemi daha çok tercih edilmiştir.

$\mathrm{Bu}$ bağlamda TPAB ile ilgili yapılan çalışmaların gün geçtikçe arttığı ve yapılan çalışmaların günümüzde farklılaştığı ve daha farklı konu alanlarında, farklı yöntemlerle yapılacak çalışmalara ihtiyaç duyulduğu söylenebilir. Bu bulguları göz önünde bulundurarak TPAB ile ilgili yapılacak çalışmalar için önerilerimiz şunlardır:

- TPAB çerçevesi ve alt boyutlarının çeşitli demografik değişkenler (yaş, cinsiyet, akademik başarı, deneyim, branş vb.) ile ilişkisini inceleyen birçok çalışma yapıldığ için öğretmenlerin teknolojiyi etkin kullanımı, derslerine entegrasyonu, TPAB becerilerinin geliştirilmesi vb. bir çok konuda farklı çalışmalara ihtiyaç duyulmaktadır.

- Matematik ve fen alanlarında olduğu gibi başta eğitime teknoloji entegrasyonunda kilit rol üstlenen bilişim teknolojileri alanı olmak üzere diğer alanlarda da TPAB ile ilgili çalışmaların arttırılması gerekmektedir. 
- Eğitime teknoloji entegrasyonu bağlamında düşünüldüğünde öğretmen adaylarıyla ilgili yapılan çalışmalar kadar görevi başında olan öğretmenlerin TPAB düzeyleri ve bunların geliştirilmesiyle ilgili çalışmaların arttırılması son derece önemlidir.

- TPAB ile ilgili yapılacak çalışmalarda nicel çalışmaların yanı sıra nitel ve karma çalışmalara ağırlık verilmesi alanyazının gelişmesine büyük bir katkı sağlayacaktır.

Sonuç olarak bu öneriler ışı̆̆ında TPAB ile ilgili yapılmış çalışmaların belirtilen bağlamlarda incelenmesinin literatüre katkı sağlayacağı, yapılmış çalışmalardaki farklılıkları ve benzerlikleri ortaya çıkaracağı ve yapılacak çalışmalara ışık tutacağı düşünülmektedir.

\section{KAYNAKLAR}

Baran, E., Chuang, H. H., \& Thompson, A. (2011). Tpack: An emerging research and development tool for teacher educators. Turkish Online Journal of Educational Technology, 10(4), 370-377.

Büyüköztürk, Ş., Kılıç Çakmak, E., Akgün, Ö.E., Karadeniz, Ş. ve Demirel, F. (2013). Bilimsel araştırma yöntemleri. Ankara: Pegem Yayınları.

Carr, A. A., Jonassen, D. H., Litzinger, M. E., \& Marra, R. M. (1998). Good ideas to foment educational revolution: The role of systematic change in advancing situated learning, constructivism, and feminist pedagogy. Educational Technology, 38(1), 5-14.

Creswell, J. W. (2013). Research design: Qualitative, quantitative, and mixed methods approaches. Sage publications.

Demir, S. \& Bozkurt, A. (2011). İlköğretim matematik öğretmenlerinin teknoloji entegrasyonundaki öğretmen yeterliklerine ilişkin görüşleri. İlkögretim Online, 10(3), 850-860.

Ferdig, R. E. (2006). Assessing technologies for teaching and learning:understanding the importance of technological pedagogical content knowledge. British Journal of Educational Technology, 37(5), 749-760.

Göktaş, Y., Küçük, S., Aydemir, M., Telli, E., Arpacık, O., Yıldırım, G., \& Reisoğlu, I. (2012). Educational technology research trends in Turkey: A content analysis of the 2000-2009 decade. Educational Sciences: Theory \& Practice, 12(1), 177-199.

Göksu, İ., Özcan, K. V., Çakır, R., Göktaş, Y. (2014). Türkiye'de öğretim tasarımı modelleriyle ilgili yapılmış çalışmalar. Illköğretim Online, 13(2), 694-709.

Kereluik, K., Mishra, P., \& Koehler, M. J. (2011). On learning to subvert signs: Literacy, technology and the TPACK framework. The California Reader, 44(2) 12-18.

Koehler, M. J. \& Mishra, P. (2005). What happens when teachers design educational technology? The development of technological pedagogical content knowledge. J. Educational Computing Research, 32(2) 131-152.

Koehler, M. J., \& Mishra, P. (2009). What is technological pedagogical content knowledge? Contemporary Issues in Technology and Teacher Education, 9(1), 60-70.

Koehler, M. (2012). TPACK image. Retrivede from http://www.matt-koehler.com/tpack/using-the-tpack-image/

Miles, M. B., \& Huberman A. M. (1994). Qualitative data analysis: An expanded sourcebook. Second Edition. California: Sage Publications.

Mishra, P., \& Koehler, M. J. (2006). Technological pedagogical content knowledge: A framework for teacher knowledge. Teachers College Record, 108(6), 1017-1054.

Pamuk, S., Ülken, A., \& Dilek, N. Ş. (2012). Öğretmen adaylarının öğretimde teknoloji kullanım yeterliliklerinin teknolojik pedagojik içerik bilgisi kuramsal perspektifinden incelenmesi. Mustafa Kemal Üniversitesi Sosyal Bilimler Enstitüsü Dergisi, 9(17), 415-438.

Shulman, L. S. (1986). Those who understand: Knowledge growth in teaching. Educational Researcher, 15(4), 414.

Shulman, L. S. (1987). Knowledge and teaching: Foundations of the new reform. Harvard Educational Review, 57(1), 1-22.

Varışoğlu, B., Şahin, A., Göktaş, Y. (2013). Türkçe eğitimi araştırmalarında eğilimler. Kuram ve Uygulamada Ĕgitim Bilimleri Dergisi (KUYEB), 13(3), 1767-1781.

Voogt, J., Fisser, P., Pareja Roblin, N., Tondeur, J., van Braak, J. (2013). Technological pedagogical content knowledge - a review of the literature. Journal of Computer Assisted Learning, 29, 109-121

Wetzel, K., Foulger, T. S., \& Williams, M.K. (Winter 2008-2009). The evolution of the required educational technology course. Journal of Computing in Teacher Education, 25 (2) 67-71.

Wu, Y.-T. (2013). Research trends in technological pedagogical content knowledge (TPACK) research: A review of empirical studies published in selected journals from 2002 to 2011. British Journal of Educational Technology 44 (3) 73-76.

Yıldırım, A. ve Şimşek, H. (2011). Sosyal bilimlerde nitel araştırma yöntemleri. Ankara: Seçkin Yayıncılık. 


\section{EKLER}

\section{Ek 1. Çalışmaların Yıllara ve Yayınlandığı Yere Göre Dağılımı}

\begin{tabular}{|c|c|c|c|c|c|c|}
\hline Dergi Adı & $\begin{array}{c}200 \\
9\end{array}$ & $\begin{array}{c}201 \\
0\end{array}$ & $\begin{array}{c}201 \\
1\end{array}$ & $\begin{array}{c}201 \\
2\end{array}$ & $\begin{array}{c}201 \\
3\end{array}$ & $\begin{array}{c}\text { Topla } \\
\text { m }\end{array}$ \\
\hline Procedia Social and Behavioral Sciences & 1 & 1 & - & 2 & - & 4 \\
\hline Kastamonu Üniversitesi Kastamonu Eğitim Dergisi & - & - & 1 & - & 1 & 2 \\
\hline İlköğretim Online Dergisi & - & - & 1 & - & - & 1 \\
\hline Ahi Evran Üniversitesi Kırşehir Eğitim Fakültesi Dergisi & - & - & 1 & - & 1 & 2 \\
\hline The Turkish Online Journal of Educational Technology & - & - & 1 & - & - & 1 \\
\hline Gaziantep Üniversitesi Sosyal Bilimler Dergisi & - & - & 1 & - & - & 1 \\
\hline Hacettepe Üniversitesi Egitim Fakültesi Dergisi & - & - & 1 & - & 1 & 2 \\
\hline $\begin{array}{l}\text { Necatibey Eğitim Fakültesi Elektronik Fen ve Matematik Eğitimi } \\
\text { Dergisi }\end{array}$ & - & - & - & 1 & - & 1 \\
\hline The Journal of Mathematics Teacher Education & - & - & - & 1 & - & 1 \\
\hline Mustafa Kemal Üniversitesi Sosyal Bilimler Enstitüsü Dergisi & - & - & - & 1 & - & 1 \\
\hline Journal of Computer Assisted Learning & - & - & - & 1 & - & 1 \\
\hline Australasian Journal of Educational Technology & - & - & - & 1 & - & 1 \\
\hline Computers \& Education & - & - & - & 1 & - & 1 \\
\hline Pamukkale Üniversitesi Eğitim Fakültesi Dergisi & - & - & - & - & 1 & 1 \\
\hline Eurasian Journal of Educational Research & - & - & - & - & 1 & 1 \\
\hline Technology, Pedagogy and Education & - & - & - & - & 1 & 1 \\
\hline International Journal of Human Sciences & - & - & - & - & 1 & 1 \\
\hline Educational Sciences: Theory \& Practice & - & - & - & - & 2 & 2 \\
\hline Batı Anadolu Eğitim Bilimleri Dergisi & - & - & - & - & 1 & 1 \\
\hline Eğitim ve Bilim & - & - & - & - & 1 & 1 \\
\hline Elektronik Sosyal Bilimler Dergisi & - & - & - & - & 1 & 1 \\
\hline Uşak Üniversitesi Sosyal Bilimler Dergisi & - & - & - & - & 1 & 1 \\
\hline Journal of Digital Learning in Teacher Education & - & - & - & - & 1 & 1 \\
\hline Ege Eğitim Dergisi & - & - & - & - & 1 & 1 \\
\hline Education As Change & - & - & - & - & 1 & 1 \\
\hline Yök Tez Veritabanı - Yüksek Lisans & 2 & 1 & 5 & 3 & 3 & 14 \\
\hline Yök Tez Veritabanı - Doktora & - & - & 1 & 2 & - & 3 \\
\hline Toplam & 3 & 2 & 12 & 13 & 19 & 49 \\
\hline
\end{tabular}




\section{Ek 2. Araştırma kapsamında incelenen çalış̧malara ait referans listesi}

Adıgüzel, A. ve Yüksel, İ. (2012). Öğretmenlerin öğretim teknolojileri entegrasyon becerilerinin değerlendirilmesi: Yeni pedagojik yaklaşımlar için nitel bir gereksinim analizi. Necatibey Eğitim Fakültesi Elektronik Fen ve Matematik Eğitimi Dergisi, 6(1).

Akkaya, E. (2009). Matematik öğretmen adaylarının türev kavramına ilişkin teknolojik pedagojik alan bilgilerinin ögrenci zorlukları bağlamında incelenmesi (Yayınlanmamış yüksek lisans tezi). Marmara Üniversitesi, İstanbul.

Alev, N., Eyuboğlu, I. S. K., Yiğit, N. (2012). Examining pre-service physics teachers' pedagogical content knowledge (PCK) with Web 2.0 through designing teaching activities. Procedia-Social and Behavioral Sciences 46, 5040-5044.

Bal, M. S. ve Karademir, N. (2013). Sosyal bilgiler öğretmenlerinin teknolojik pedagojik alan bilgisi (tpab) konusunda öz-değerlendirme seviyelerinin belirlenmesi. Pamukkale Üniversitesi Eğitim Fakültesi Dergisi, 34(11), 15-32.

Bilici, S. C. (2012). Fen bilgisi ögretmen adaylarının teknolojik pedagojik alan bilgisi ve özyeterlikleri (Yayınlanmamış doktora tezi). Gazi Üniversitesi, Ankara.

Bilici, S. C., Yamak, H., Kavak, N. ve Guzey, S. S. (2013) Technological pedagogical content knowledge selfefficacy scale (TPACK-SeS) for pre-service science teachers: Construction, validation and reliability. Eurasian Journal of Education Research, 52, 37-60.

Bozkurt, A. ve Cilavdaroğlu, A. K. (2011). Matematik ve sınıf öğretmenlerinin teknolojiyi kullanma ve derslerine teknolojiyi entegre etme algıları. Kastamonu Ĕgitim Dergisi, 19(3), 859-870.

Bulut, A. (2012). Investigating perceptions of preservice mathematics teachers on their technological pedagogical content knowledge (TPACK) regarding geometry (Unpublished Master Dissertation). Middle East Technical University, Ankara.

Canbolat, N. (2011). Matematik öğretmen adaylarının teknolojik pedagojik alan bilgileri ile düşünme stilleri arasindaki ilişkinin incelenmesi (Yüksek Lisans Tezi). Selçuk Üniversitesi, Konya.

Demir, S. ve Bozkurt, A. (2011). İlköğretim matematik öğretmenlerinin teknoloji entegrasyonundaki öğretmen yeterliklerine ilişkin görüşleri. Ilköğretim Online, 10(3), 850-860.

Doğan, M. (2012). Prospective turkish primary teachers'views about the use of computers in mathematics education. Journal of mathematics Teacher Education, 15, 329-341.

Erdoğan, A. ve Şahin, İ. (2010). Relationship between math teacher candidates' technological pedagogical and content knowledge (TPACK) and achievement levels. Procedia-Social and Behavioral Sciences, 2(2), $2707-2711$.

Ergene, B. (2011). Matematik öğretmen adaylarının türev kavramina ilişkin teknolojik pedagojik alan bilgilerinin çoklu temsiller bileşeninde incelenmesi (Yayınlanmamış yüksek lisans tezi). Marmara Üniversitesi, İstanbul.

Gündoğmuş, N. (2013). Öğretmen adaylartnin teknolojik pedagojik alan bilgileri ile ögrenme stratejileri arasindaki ilişkinin incelenmesi (Yüksek Lisans Tezi). Necmettin Erbakan Üniversitesi, Konya.

Horzum, M. B. (2013) An investigation of the technological pedagogical content knowledge of pre-service teachers. Technology. Pedagogy and Education, 22(3), 303-317.

Karadeniz, S. ve Vatanartıran, S. (2013). Adaptation of a TPACK survey to Turkish for secondary school teachers. International Journal of Human Sciences, 10(2), 34-47.

Karakaya, Ç. (2013). Teknolojik pedagojik alan bilgisi çerçevesinde önerilen eğitim programı sürecinde öğretmen adaylarının şekillendirici ölçme ve değerlendirme bilgi ve becerilerinin gelişiminin incelenmesi (Yayınlanmamış yüksek lisans tezi). Gazi Üniversitesi, Ankara.

Kaya, Z. (2010). Fen ve teknoloji ögretmen adaylarının fotosentez ve hücresel solunum konusundaki teknolojik pedagojik alan bilgisinin araştırılması (Yayınlanmamış yüksek lisans tezi). Fırat Üniversitesi, Elazı̆̆.

Kaya, S. ve Dağ, F. (2013). Turkish adaptation of technological pedagogical content knowledge survey for elementary teachers. Educational Sciences: Theory \& Practice, 13(1), 291-306.

Kaya, Z., Kaya, O. N. ve Emre, İ. (2013).Teknolojik pedagojik alan bilgisi (TPAB) ölçeği'nin Türkçeye uyarlanması. Kuram ve Uygulamada Eğitim Bilimleri,13(4), 2355-2377.

Kaya, Z. ve Yılayaz, Ö. (2013). Öğretmen eğitimine teknoloji entegrasyonu modelleri ve teknolojik pedagojik alan bilgisi. Batı Anadolu Eğitim Bilimleri Dergisi, 4(8), 57-83.

Kılıç, A. (2011). Fen ve teknoloji öğretmen adaylarının elektrik akımı konusundaki teknolojik pedagojik alan bilgilerinin ve sınıf içi uygulamalarının araştırlması (Yayınlanmamış yüksek lisans tezi). Fırat Üniversitesi, Elazı̆g.

Koçoğlu, Z. (2009). Exploring the technological pedagogical content knowledge of pre-service teachers in language education. Procedia-Social and Behavioral Sciences, 1(1), 2734-2737.

Kokoç, M. (2012). Karma mesleki gelişim programı sürecinde ilköğretim sinıf öğretmenlerinin teknolojik pedagojik alan bilgisi deneyimleri üzerine bir çalışma (Yayınlanmamış yüksek lisans tezi). Karadeniz Teknik Üniversitesi, Trabzon. 
Konokman, G. Y., Yelken, T. Y. ve Tokmak, H. S. (2013). Sınıf öğretmeni adaylarının TPAB'lerine ilişkin algılarının çeşitli değişkenlere göre incelenmesi: Mersin Üniversitesi örneği. Kastamonu Eğitim Fakültesi Dergisi, 12(1), 665-684.

Köseoğlu, P. (2012). Hacettepe University prospective biology teachers' self-confidence in terms of technological pedagogical content. Procedia-Social and Behavioral Sciences, 46, 931-934.

Kurt, G. (2012). Developing technological pedagogical content knowledge of Turkish pre-service teachers of English through a design study (Unpublished Doctoral thesis). Yeditepe University, İstanbul.

Mutluoğlu, A. (2012). Ilkögretim matematik ögretmenlerinin ögretim stili tercihlerine göre teknolojik pedagojik alan bilgilerinin incelenmesi (Yüksek Lisans Tezi). Selçuk Üniversitesi, Konya.

Övez, F. T. D. ve Akyüz, G. (2013). İlköğretim matematik öğretmeni adaylarının teknolojik pedagojik alan bilgisi yapılarının modellenmesi. Eğitim ve Bilim, 38(170), 321-334.

Özgen, K., Narlı, S. ve Alkan, H. (2013). Matematik öğretmen adaylarının teknolojik pedagojik alan bilgileri ve teknoloji kullanım sıklığı algılarının incelenmesi. Elektronik Sosyal Bilimler Dergisi, 12(44), 31-51.

Öztürk, E. (2013). Sınıf öğretmeni adaylarının teknolojik pedagojik alan bilgilerinin bazı değişkenler açısından değerlendirilmesi. Uşak Üniversitesi Sosyal Bilimler Dergisi, 13, 223-238.

Öztürk, E. ve Horzum, M. B. (2011). Teknolojik pedagojik içerik bilgisi ölçeği'nin türkçeye uyarlaması. Ahi Evran Üniversitesi Kırşehir Eğitim Fakültesi Dergisi, 12(3).

Pamuk, S. (2012). Understanding preservice teachers' technology use through TPACK framework. Journal of Computer Assisted Learning, 28, 425-439.

Pamuk, S. Ülken, A. ve Dilek, N. Ş. (2012). Öğretmen adaylarının öğretimde teknoloji kullanım yeterliliklerinin teknolojik pedagojik içerik bilgisi kuramsal perspektifinden incelenmesi. Mustafa Kemal Üniversitesi Sosyal Bilimleri Enstitüsü Dergisi, 9(17), 415-438.

Savaş, M. (2011). Investigating pre-service science teachers' perceived technological pedagogical content knowledge regarding genetics (Unpublished master thesis). Middle East Technical University, Ankara.

Semiz, K. (2011). Pre-service physical education teachers' technological pedagogical content knowledge, technology integration self-efficacy and instructional technology outcome expectations (Unpublished master thesis). Middle East Technical University, Ankara.

Semiz, K., \& İnce, M. L. (2012). Pre-service physical education teachers'technological pedagogical content knowledge, technology integration self-efficacy and instructional technology outcome expectations. Australasian Journal of Educational Technology, 28(7), 1248-1265.

Şahin, İ. (2011). Development of survey of technological pedagogical and content knowledge (tpack). The Turkish Online Journal of Educational Technology, 10(1), 97-105.

Şahin, İ., Çelik, İ., Aktürk, A. O. ve Aydın, M. (2013). Analysis of relationships between technological pedagogical content knowledge and educational internet use. Journal of Digital Learning in Teacher Education, 29(4), 110-117.

Şahin, S. M., Yenmez, A. A., Özpınar, İ. ve Köğce, D. (2013). Öğretmen Adaylarının Teknolojik Pedagojik Alan Bilgisi Modeline Uygun Bir Hizmet Öncesi Eğitim Programının Bileşenlerine İlişkin Görüşleri. Hacettepe Üniversitesi Ĕgitim Fakültesi Dergisi, Özel Sayı (1), 271-286.

Şimşek, Ö., Demir, S., Bağçeci, B. ve Kinay, İ. (2013). Öğretim elemanlarının teknopedagojik eğitim yeterliliklerinin çeşitli değişkenler açısından incelenmesi. Ege Ĕ̆itim Dergisi, 14(1), 1-23.

Timur, B. (2011). Fen bilgisi ögretmen adaylarının kuvvet ve hareket konusundaki teknolojik pedagojik alan bilgilerinin gelişimi (Yayınlanmamış doktora tezi). Gazi Üniversitesi, Ankara.

Timur, B. ve Taşar, M. F. (2011). Teknolojik pedagojik alan bilgisi öz güven ölçeğinin (TPABÖGÖ) Türkçe'ye uyarlanmas1. University of Gaziantep Journal of Social Sciences, 10(2).

Tokmak, H. S. (2013). Changing preschool teacher candidates' perceptions about technology integration in a TPACK-based material design course. Education as Change, 17(1), 115-129.

Tokmak, H. S., Konokman, G. Y. ve Yelken, T. Y. (2013). Mersin üniversitesi okul öncesi öğretmen adaylarının teknolojik pedagojik alan bilgisi (tpab) özgüven algılarının incelenmesi. Ahi Evran Üniversitesi Kirşehir Eğitim Fakültesi Dergisi, 14(1), 35-51.

Uğurlu, R. (2009). Teknolojik pedagojik alan bilgisi çerçevesinde önerilen eğitim programı sürecinde ögretmen adaylarının şekillendirici ölçme ve değerlendirme bilgi ve becerilerinin gelişiminin incelenmesi (Yayınlanmamış yüksek lisans tezi). Marmara Üniversitesi, İstanbul.

Uygun, E. (2013). Learning by design: An integrated approach for technological pedagogical content knowledge development (Unpublished master thesis). Middle East Technical University, Ankara.

Yurdakul, I. K. (2011). Öğretmen adaylarının teknopedagojik eğitim yeterliklerinin bilgi ve iletişim teknolojilerini kullanımları açısından incelenmesi. Hacettepe Üniversitesi Ĕ̈itim Fakültesi Dergisi, 40, 397-408.

Yurdakul, I. K., Odabaşı, H. F., Kılıçer, K., Çoklar, A. N., Birinci, G., \& Kurt, A. A. (2012). The development, validity and reliability of TPACK-deep: A technological pedagogical content knowledge scale. Computers \& Education 58, 964-977. 